\title{
Molecular analysis revealed genetic decline in hatchery-produced Cyprinus carpio
}

\author{
Sumra Naz and Khalid Abbas* \\ Aquaculture Biotechnology Laboratory, Department of Zoology, Wildlife and Fisheries, University of Agriculture, \\ Faisalabad-38040, Pakistan \\ *Corresponding author's e-mail: dr.abbas@uaf.edu.pk
}

\begin{abstract}
Population genetic structure of cultured fish species is vital for improving the fisheries management and stock enhancement programs. The genetic variability and population genetic structure at fourteen microsatellite loci of a total 210 individuals of Cyprinus carpio from six selected hatcheries were analyzed. The data obtained through microsatellite markers showed a lowto-moderate level of genetic diversity in terms of allele numbers $(\mathrm{Na})$, allelic richness $(\mathrm{Ar})$, effective allele numbers $(\mathrm{Nae})$ and observed heterozygosity $(\mathrm{Ho})$ in all the populations. At the examined loci, 32 out of 84 possible tests were observed to be significantly $(P<0.05)$ deviated from the Hardy-Weinberg equilibrium. Maximal gene flow $(\mathrm{Nm})$ and lower population differentiation $\left(F_{S T}\right)$ was experienced among populations. However, significant $(P<0.05)$ differentiation was observed among some populations. An analysis of the distribution of genetic variation indicated within individual was very high (69.07\%), while, among individuals within populations and among populations was low ( $29.56 \%$ and $1.37 \%$, respectively). Recent bottleneck was detected with the shifted mode. Phylogenetic neighbor joining tree analysis showed the two distinct clusters. The inferences of this study would be helpful for setting up effective management strategies for the better conservation of genetic integrity in the hatchery stocks of $C$. carpio.
\end{abstract}

Keywords: Population's structure, common carp, microsatellite markers, hatchery populations.

\section{INTRODUCTION}

Aquaculture practices are probably known to lessen the genetic variability in farm raised fish stocks by random genetic drift, inbreeding and founder effects, usually represent the distant gene pools relative to the wild populations (Wang et al., 2011). Genetic diversity and its adaptation to habitats subjected to several environmental stressors, is prerequisites for the survival and preservation of a species. Moreover, higher genetic diversity level improves the competence among individuals and increases the probability of species survival (Diz and Presa, 2009). Loss of genetic variability may lead to potentially harmful effects on the various essential traits like growth, environmental adaptability and disease resistance that would impair the efficient aquaculture (Allendorf et al., 2008).

Hatcheries involved in the fish spawn production are reported not to be properly managed due to several reasons, such as lack of facilities for maintaining the required number of quality breeders, absence of knowledge about the adverse effects of poor management, lack of technical knowledge and inclusively high competition in fish seed market (Ovenden $e t$ $a l ., 2016)$. Negative selection associated with inbreeding and hybridization are traditional hatchery practices that separately or jointly accountable for the deterioration of quality fish seed thus, limiting the effectiveness of release activities (Loukovitis et al., 2014). Release of farm raised fish with reduced genetic diversity to the natural systems may decrease the genetic variability of natural populations with less production rate and fitness. Additionally, when hatchery populations are genetically diverse from wild populations, severe fitness reductions and changes in genetic structure of the natural fish populations may occur (Milot et al., 2013). The fish Cyprinus carpio (Common Carp) is a freshwater teleost belonging to the largest Cyprinidae family is being cultured throughout the world (Xu et al., 2014). Initially, it was introduced for the purpose of aquaculture, but now it has been well settled as a wild species into freshwater ecosystems of Pakistan. It also contributes to the country's aquaculture production significantly but the distribution range of natural populations of the cyprinid family has been severely reduced (Ahmed and Abbas, 2018). Several anthropogenic pressures and translocation of exotic wild or captive individuals may have serious effects on the genetic makeup and evolutionary path of wild populations resulting in demographic decline of C. carpio (Sharpe and Hendry, 2009; Gottschalk et al., 2011). 
In hatcheries, to keep the production cost to a minimum $C$. carpio is constantly bred with a small number of effective parents. As a result, genetic erosion may have arisen through the effects of bottleneck, inbreeding and genetic drift. Moreover, hatchery owners, sometimes perform cross breeding between various Common Carp strains to produce the attractive colored fish to meet the public demands. That may lead to the introgression among genes causing the respective strain to lose their genetic integrity. All of these undesirable management practices have been described as potential constraints in Common Carp culture based fisheries (Boudry et al., 2002; Elliott and Reilly, 2003).

DNA markers have proved to be an excellent indicator of genetic variability among and within populations of many fishery animals (Lee and Hur, 2012). Among the available molecular markers, microsatellites have become the marker of choice for studying the fish population genetics (Kim et al., 2013) having the multiple alleles that are highly polymorphic among individuals. The polymorphism acquired through these markers has provided useful information to be considered in the management of hatchery fish stocks (Defaveri et al., 2013), population genetic analysis and conservation of biodiversity. A greater understanding of the ecological importance of genetic variability is needed to develop environmental policies, fisheries and development perspectives that will aid in the country's long-term management of freshwater fish species. The key objective of this study was to evaluate the extent of genetic variability and population structure in hatchery populations of $C$. carpio by using microsatellite markers.

\section{MATERIALS AND METHODS}

Fish Sampling and DNA isolation: A total of 210 individuals of $C$. carpio were collected from 6 selected hatcheries (35 individuals from each site) of Punjab, Pakistan including Rawalpindi hatchery (RWP), Gujranwala hatchery (GUJW), Lahore hatchery (LHR), Faisalabad hatchery (FSD), Khanewal hatchery (KHAW) and Bahawalpur hatchery (BHW) (Fig. 1). The sampled individuals were identified and confirmed to be $C$. carpio using the key features (Bakos and Gorda, 2001) and were named after the first letters of sampling sites. The tissues of dorsal muscle were removed and stored at $-20^{\circ} \mathrm{C}$. Total genomic DNA was extracted by using the standard phenol/chloroform DNA isolation technique of Sambrook and Russell (2001). The isolated DNA was visualized for quality and quantity by $0.8 \%$ agarose gel electrophoresis and NanoDrop spectrophotometer (Thermo Scientific) at $260 \mathrm{~nm}$, respectively.

PCR amplification of microsatellite loci: A total of fourteen species specific microsatellite loci developed by $\mathrm{Li}$ et al. (2007) were amplified through gradient thermal cycler (Table 1). The PCR amplification was carried out in a $20 \mu \mathrm{L}$ eppendorf tube that contained template DNA (approximately 50ng), PCR master mix 2X (Thermo Scientific) $(12 \mu \mathrm{L})$ and each forward and reverse primer $(2 \mu \mathrm{L})$ in a thermocycler.

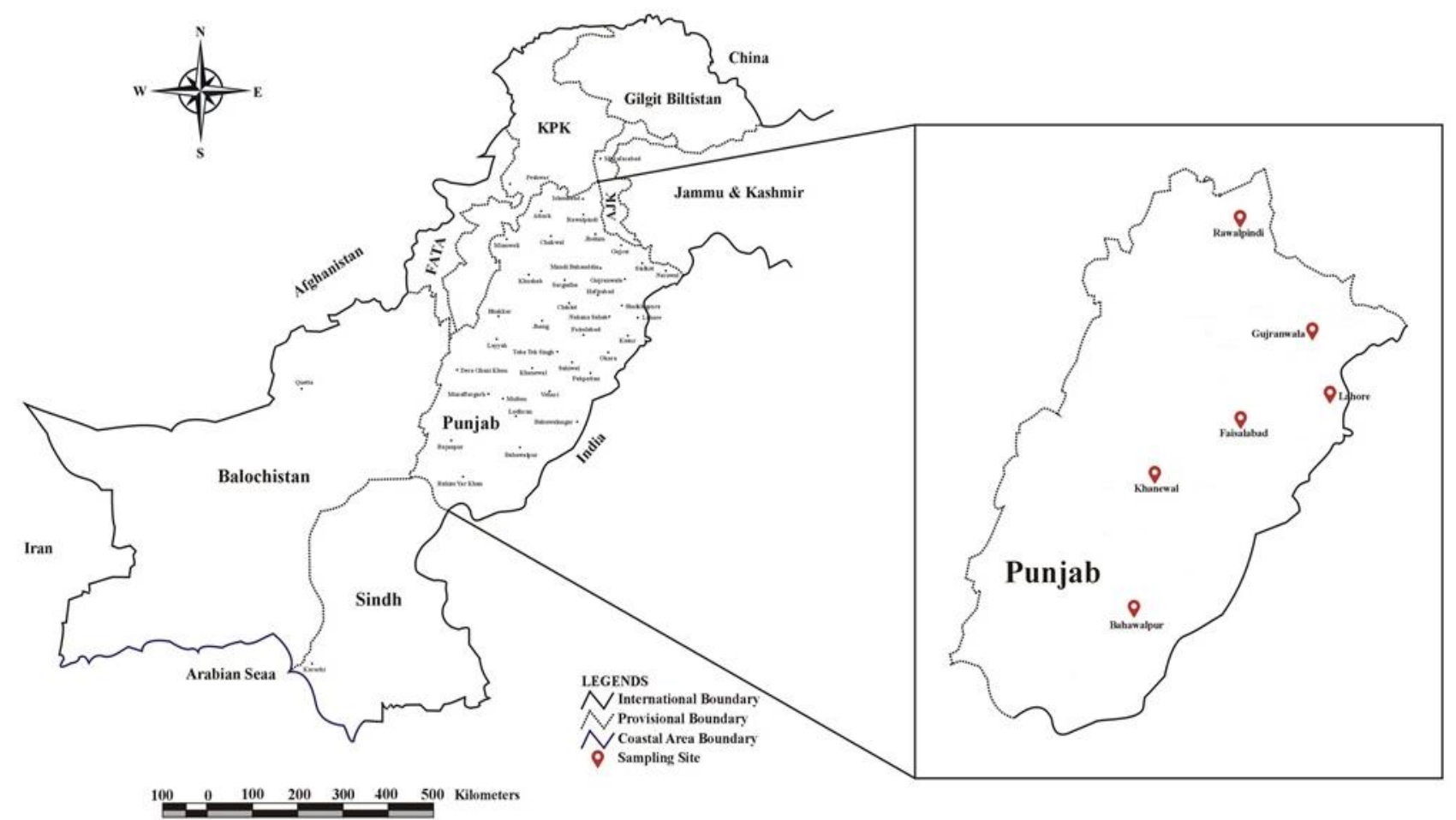

Figure 1. Map of Punjab, Pakistan showing the fish sampling sites 
Genetic decline in C. carpio

Table 1. Characteristics of Microsatellite loci developed by Li et al. (2007)

\begin{tabular}{|c|c|c|c|c|c|}
\hline $\begin{array}{l}\text { Sr. } \\
\text { No. }\end{array}$ & Locus & Repeat motifs & Accession No. & Primer sequence $\left(5^{\prime}-3^{\prime}\right)$ & $\mathbf{T a}\left({ }^{\circ} \mathbf{C}\right)$ \\
\hline \multirow[t]{2}{*}{1} & \multirow[t]{2}{*}{ HLJ041 } & \multirow[t]{2}{*}{$(\mathrm{CA})_{24}$} & \multirow[t]{2}{*}{ FJ403115 } & F: AGACCACCGCAGTAACAA & \multirow[t]{2}{*}{53} \\
\hline & & & & R: GACTCACTCAGCACCAGA & \\
\hline \multirow[t]{2}{*}{2} & \multirow[t]{2}{*}{ HLJ044 } & \multirow[t]{2}{*}{$(\mathrm{CA})_{28}$} & \multirow[t]{2}{*}{ FJ403116 } & F: GTACAGCGTGACAGCATT & \multirow[t]{2}{*}{53} \\
\hline & & & & R: AAGTTCATCGGTGTCCTC & \\
\hline \multirow[t]{2}{*}{3} & \multirow[t]{2}{*}{ HLJ046 } & \multirow[t]{2}{*}{$(\mathrm{GT})_{14}$} & \multirow[t]{2}{*}{ FJ403117 } & F: AACCCTGAACTCACAAAC & \multirow[t]{2}{*}{53} \\
\hline & & & & R: CACGGAAACTGAGAAGAC & \\
\hline \multirow[t]{2}{*}{4} & \multirow[t]{2}{*}{ HLJ049 } & \multirow[t]{2}{*}{$(\mathrm{GT})_{28}$} & \multirow[t]{2}{*}{ FJ403118 } & F: GATTTGTGCTCCTCAACC & \multirow[t]{2}{*}{54} \\
\hline & & & & R: CTGTCACTTCTCCTTCCA & \\
\hline \multirow[t]{2}{*}{5} & \multirow[t]{2}{*}{ HLJ058 } & \multirow[t]{2}{*}{$(\mathrm{CA})_{21}$} & \multirow[t]{2}{*}{ FJ403123 } & F: CAGATGGCAGACAGGTAA & \multirow[t]{2}{*}{53} \\
\hline & & & & R: GAGCAAGTGAGGGAACAG & \\
\hline \multirow[t]{2}{*}{6} & \multirow[t]{2}{*}{ HLJ060 } & \multirow[t]{2}{*}{$(\mathrm{GT})_{23}$} & \multirow[t]{2}{*}{ FJ403125 } & F: CGATCACTGGCAAGATTA & \multirow[t]{2}{*}{54} \\
\hline & & & & R: ATGGACTACACCTCACCC & \\
\hline \multirow[t]{2}{*}{7} & \multirow[t]{2}{*}{ HLJ379 } & $(\mathrm{CT})_{13}$ & JN687097 & F: GGGGAGACGAGAAGTGCA & 54 \\
\hline & & & & R: AGCAGGTCTGTGGGCAAG & \\
\hline 8 & HLJ392 & $(\mathrm{CA})_{22}$ & JN687127 & F: GGCTACAAGGCAACACTG & 54 \\
\hline & & & & R: TGCGGTTAATGAGGTCTG & \\
\hline 9 & HLJ393 & $(\mathrm{CT})_{10}$ & JF764814 & F: TGCGGTCATTACTCATTCG & 54 \\
\hline & & & & R: CCCAGCACCTGTTTCCAC & \\
\hline 10 & HLJ643 & $(\mathrm{CA})_{7}$ & JF764942 & F: CCGACTCAGTGTTCAATT & 50 \\
\hline & & & & R: GAAACCTAAGTCCCCAAC & \\
\hline 11 & HLJ806 & $(\mathrm{CA})_{48}$ & FJ403185 & F: GGTGTCAGGCTTTAGTCC & 48 \\
\hline & & & & R: CATCTGAGTTTTCTCCAAGT & \\
\hline 12 & HLJ809 & $(\mathrm{CA})_{12}$ & FJ403187 & F:ATCATCACAGCCAAAGAAGT & 48 \\
\hline & & & & R:TACGGACATAGTGCAGACAA & \\
\hline 13 & HLJ817 & $(\mathrm{GT})_{22}$ & JN687184 & F: GACGATCCAGCAGCAATG & 48 \\
\hline & & & & R: CTCTTCCTAAAGCСТCAAA & \\
\hline 14 & HLJ855 & $(\mathrm{AC})_{44}$ & FJ403190 & F: CGACCGAACTCAGAACAC & 48 \\
\hline & & & & R: GAGCACCGCATTAACAGA & \\
\hline
\end{tabular}

$\mathrm{F}$-forward, $\mathrm{R}$-reverse, $\mathrm{Ta}$ - primer specific annealing temperature

PCR cycling programs were carried out as first step of denaturation, for $5 \mathrm{~min}$ at $94^{\circ} \mathrm{C}$, followed by 35 cycles of 30 seconds at $94^{\circ} \mathrm{C}, 30$ seconds at respective annealing temperature, $1 \mathrm{~min}$ at $72^{\circ} \mathrm{C}$ and finally an elongation for $5 \mathrm{~min}$ at $72^{\circ} \mathrm{C}$. After the PCR amplification, $5 \mu \mathrm{L}$ of PCR product and $1 \mu \mathrm{L}$ of loading dye was mixed in a separate tube. PCR products were electrophoretically isolated on polyacrylamide gels $(5 \%)$ and visualized by using Gel documentation chamber (UVCI, Major Science, USA). The bands were scored manually and the allele sizes were assessed with reference to the pUC18DNA sequence ladder (Thermo Fisher Scientific, USA).

Data analyses: Prior to data analyses, MICROCHECKER (ver. 2.2.1) was applied to test for scoring errors due to null alleles, stuttering bands or dropout of large allele (Oosterhout et al., 2004). Microsatellite allelic diversity was computed as the alleles numbers $(\mathrm{Na})$, allelic richness $(\mathrm{Ar})$, observed heterozygosity $(\mathrm{Ho})$ and expected heterozygosity $(\mathrm{He})$; additionally, the inbreeding coefficient $\left(F_{I S}\right)$ was quantified using FSTAT (ver. 2.9.3.2) (Goudet, 2002). Each population was tested for departure from Hardy Weinberg equilibrium using the Markov-chain random walk algorithm in POPGENE (ver. 1.31) (Yeh et al., 1999). The significance level for this test was adjusted by sequential Bonferroni correction (Rice, 1989).

The genetic differentiation was estimated with pairwise $F_{S T}$ values (Weir and Cockerham's, 1984). A Hierarchical partition of genetic variation was measured by AMOVA incorporated in ARLEQUIN (ver. 3.1) (Excoffier et al., 2005). The Bottleneck software (ver. 1.2.02) was used to assess the probability of recent bottleneck events based on either deficit or excess of heterozygosity (Piry et al., 1999). TFPGA software based on Nei's (1972) unbiased genetic distance was used to construct UPGMA dendrogram (Miller, 1997). Finally, the population structure was investigated by employing the program STRUCTURE (ver. 2.3.2) (Pritchard et al., 2000; Falush et al., 2003). For each K value, seven independent runs were undertaken and number of genetic clusters was determined with STRUCTURE HARVESTER (Earl and Vonholdt, 2012) to verify the consistency of the results according to Evanno et al. (2005). 


\section{RESULTS}

Genetic Diversity: Six hatchery reared populations of $C$. carpio $(\mathrm{n}=35)$ were screened for genetic diversity at fourteen polymorphic microsatellite loci. The MICROCHECKER analysis showed no evidence of dropout of large alleles and null alleles or allele stuttering in the genotypes. The allele numbers for all the examined microsatellite loci ranged from 2 to 5 with mean values varied from 3.500 to 4.000 and the average values of effective allele number from 2.881 to 3.464 . Overall, the observed heterozygosity at all the loci was lesser than the corresponding expected heterozygosity. The mean value of observed and expected heterozygosity ( $\mathrm{Ho} \& \mathrm{He}$ ) varied from 0.455-0.555 and 0.634-0.696, respectively. Among all the populations, LHR hatchery showed the maximum genetic variability, while BWP hatchery exhibited the minimum diversity. The mean values of inbreeding coefficient $\left(F_{I S}\right)$ were found positive and ranged from 0.210 for LHR to 0.357 for BWP, populations indicating the loss of heterozygosity within populations. After sequential Bonferroni correction, among the 84 loci population cases, 32 cases were found to be significantly deviated from $H W E$ (Table 2).

Genetic Structure: The level of genetic differentiation was quantified with the pairwise $F_{S T}$ values that revealed a low, but significant level of differentiation between the populations. The pairwise $F_{S T}$ estimates ranged from 0.0035 to 0.0241 . The maximum differentiation was noted between the LHR-BWP while, the least was noted between the GUJWFSD populations pairs. Unbiased genetic distance $(G D)$ among pair of populations exposed considerable but significant $(P<0.05)$ variation in magnitude. The results were quite parallel when genetic distances were analyzed (Table 3) for genetic differentiation and genetic distance values for

Table 2. Genetic diversity at various microsatellite loci in hatchery population of $C$. carpio.

\begin{tabular}{|c|c|c|c|c|c|c|c|c|c|c|c|c|c|c|c|c|}
\hline \multirow[t]{2}{*}{ Populations } & \multirow[t]{2}{*}{ Parameters } & \multicolumn{14}{|c|}{ Loci } & \multirow[t]{2}{*}{ Average } \\
\hline & & HLJ041 & HLJ044 & HLJ046 & HLJ049 & HLJ058 & HLJ060 & HLJ379 & HLJ392 & HLJ393 & HLJ643 & HLJ806 & HLJ809 & HLJ817 & HLJ855 & \\
\hline \multirow[t]{8}{*}{ RWP } & $\mathrm{Na}$ & 3 & 4 & 4 & 4 & 4 & 3 & 4 & 2 & 4 & 4 & 4 & 3 & 4 & 4 & 3.643 \\
\hline & $A r$ & 3 & 4 & 4 & 4 & 4 & 3 & 4 & 2 & 4 & 4 & 4 & 3 & 4 & 4 & 3.643 \\
\hline & Nae & 2.725 & 3.074 & 3.427 & 2.716 & 3.571 & 2.615 & 2.839 & 1.974 & 2.927 & 3.614 & 3.684 & 2.845 & 3.695 & 3.436 & 3.081 \\
\hline & Ho & 0.571 & 0.543 & 0.571 & 0.371 & 0.4 & 0.486 & 0.229 & 0.486 & 0.200 & 0.486 & 0.486 & 0.514 & 0.571 & 0.429 & 0.453 \\
\hline & $\mathrm{He}$ & 0.633 & 0.675 & 0.708 & 0.632 & 0.72 & 0.618 & 0.648 & 0.493 & 0.658 & 0.723 & 0.729 & 0.649 & 0.729 & 0.709 & 0.666 \\
\hline & 1-Ho/He & 0.098 & 0.195 & 0.193 & 0.413 & 0.444 & 0.213 & 0.647 & 0.014 & 0.696 & 0.328 & 0.333 & 0.208 & 0.217 & 0.395 & 0.314 \\
\hline & $F_{I S}$ & 0.112 & 0.209 & 0.207 & 0.406 & 0.456 & 0.227 & 0.646 & 0.030 & 0.704 & 0.341 & 0.346 & 0.221 & 0.230 & 0.408 & 0.324 \\
\hline & PHWE & $0.0925^{\mathrm{NS}}$ & $0.0065^{\mathrm{NS}}$ & $0.0097^{\mathrm{NS}}$ & $0.0001^{*}$ & $0.0000^{*}$ & $0.0019^{\mathrm{NS}}$ & $0.0000^{*}$ & $0.8581^{\mathrm{NS}}$ & $0.0000^{*}$ & $0.0084^{\mathrm{NS}}$ & $0.0065^{\mathrm{NS}}$ & $0.1291^{\mathrm{NS}}$ & $0.0063^{\mathrm{NS}}$ & $0.0001^{*}$ & ----- \\
\hline \multirow[t]{8}{*}{ GUJW } & $\mathrm{Na}$ & 4 & 4 & 4 & 4 & 5 & 2 & 5 & 3 & 5 & 5 & 4 & 3 & 4 & 4 & 4 \\
\hline & $A r$ & 4 & 4 & 4 & 4 & 5 & 2 & 5 & 3 & 5 & 5 & 4 & 3 & 4 & 4 & 4 \\
\hline & Nae & 3.598 & 3.361 & 3.215 & 2.819 & 3.840 & 1.993 & 4.399 & 2.626 & 4.614 & 4.649 & 3.566 & 2.886 & 3.798 & 3.129 & 3.464 \\
\hline & $\mathrm{Ho}$ & 0.543 & 0.486 & 0.457 & 0.371 & 0.514 & 0.371 & 0.514 & 0.600 & 0.571 & 0.457 & 0.543 & 0.486 & 0.657 & 0.457 & 0.502 \\
\hline & $\mathrm{He}$ & 0.722 & 0.702 & 0.689 & 0.645 & 0.740 & 0.498 & 0.773 & 0.619 & 0.783 & 0.785 & 0.720 & 0.653 & 0.737 & 0.680 & 0.696 \\
\hline & 1-Ho/He & 0.248 & 0.308 & 0.337 & 0.425 & 0.305 & 0.255 & 0.335 & 0.031 & 0.271 & 0.418 & 0.246 & 0.256 & 0.108 & 0.328 & 0.276 \\
\hline & $F_{I S}$ & 0.262 & 0.322 & 0.338 & 0.436 & 0.318 & 0.268 & 0.347 & 0.045 & 0.265 & 0.429 & 0.228 & 0.270 & 0.122 & 0.341 & 0.285 \\
\hline & PHWE & $0.0421^{\mathrm{NS}}$ & $0.0032^{\mathrm{NS}}$ & $0.0031^{\mathrm{NS}}$ & $0.0025^{\mathrm{NS}}$ & $0.0237^{\mathrm{NS}}$ & $0.1096^{\mathrm{NS}}$ & $0.0004^{*}$ & $0.4898^{\mathrm{NS}}$ & $0.0016^{\mathrm{NS}}$ & $0.0000^{*}$ & $0.0837^{\mathrm{NS}}$ & $0.0334^{\mathrm{NS}}$ & $0.0772^{\mathrm{NS}}$ & $0.0067^{\mathrm{NS}}$ & ----- \\
\hline \multirow[t]{8}{*}{ LHR } & $\mathrm{Na}$ & 4 & 5 & 4 & 2 & 5 & 3 & 5 & 3 & 5 & 5 & 4 & 3 & 4 & 4 & 4 \\
\hline & $A r$ & 4 & 5 & 4 & 2 & 5 & 3 & 5 & 3 & 5 & 5 & 4 & 3 & 4 & 4 & 4 \\
\hline & Nae & 3.333 & 3.834 & 3.153 & 1.985 & 4.391 & 2.528 & 4.09 & 2.966 & 4.479 & 4.588 & 3.407 & 2.859 & 3.635 & 3.013 & 3.447 \\
\hline & Ho & 0.514 & 0.571 & 0.429 & 0.400 & 0.514 & 0.543 & 0.857 & 0.514 & 0.600 & 0.714 & 0.514 & 0.486 & 0.486 & 0.629 & 0.555 \\
\hline & $\mathrm{He}$ & 0.700 & 0.739 & 0.683 & 0.496 & 0.772 & 0.604 & 0.755 & 0.663 & 0.777 & 0.782 & 0.706 & 0.65 & 0.725 & 0.668 & 0.694 \\
\hline & 1-Ho/He & 0.266 & 0.227 & 0.372 & 0.193 & 0.334 & 0.101 & -0.135 & 0.225 & 0.228 & 0.087 & 0.272 & 0.252 & 0.330 & 0.058 & 0.201 \\
\hline & $F_{I S}$ & 0.279 & 0.217 & 0.385 & 0.208 & 0.347 & 0.116 & -0.12 & 0.215 & 0.241 & 0.101 & 0.285 & 0.247 & 0.343 & 0.074 & 0.210 \\
\hline & PHWE & $0.0585^{\mathrm{NS}}$ & $0.0041^{\mathrm{NS}}$ & $0.0012^{\mathrm{NS}}$ & $0.2163^{\mathrm{NS}}$ & $0.0004 *$ & $0.0243^{\mathrm{NS}}$ & $0.0000^{*}$ & $0.0153^{\mathrm{NS}}$ & $0.0003^{*}$ & $0.0002 *$ & $0.0286^{\mathrm{NS}}$ & $0.0208^{\mathrm{NS}}$ & $0.0008^{*}$ & $0.7885^{\mathrm{NS}}$ & ----- \\
\hline \multirow[t]{8}{*}{ FSD } & $\mathrm{Na}$ & 4 & 4 & 3 & 4 & 4 & 2 & 4 & 3 & 4 & 5 & 4 & 3 & 4 & 4 & 3.714 \\
\hline & $A r$ & 4 & 4 & 3 & 4 & 4 & 2 & 4 & 3 & 4 & 5 & 4 & 3 & 4 & 4 & 3.714 \\
\hline & Nae & 2.955 & 3.215 & 2.672 & 2.598 & 3.32 & 1.901 & 3.535 & 2.762 & 3.598 & 4.658 & 3.475 & 2.941 & 3.194 & 3.551 & 3.17 \\
\hline & $\mathrm{Ho}$ & 0.429 & 0.400 & 0.343 & 0.457 & 0.514 & 0.600 & 0.514 & 0.400 & 0.514 & 0.600 & 0.457 & 0.514 & 0.543 & 0.457 & 0.481 \\
\hline & $\mathrm{He}$ & 0.662 & 0.689 & 0.626 & 0.615 & 0.699 & 0.474 & 0.717 & 0.638 & 0.722 & 0.785 & 0.712 & 0.660 & 0.687 & 0.718 & 0.672 \\
\hline & 1-Ho/He & 0.352 & 0.419 & 0.452 & 0.257 & 0.265 & -0.266 & 0.283 & 0.373 & 0.288 & 0.236 & 0.358 & 0.221 & 0.210 & 0.363 & 0.272 \\
\hline & $F_{I S}$ & 0.349 & 0.431 & 0.464 & 0.270 & 0.277 & -0.253 & 0.296 & 0.385 & 0.301 & 0.250 & 0.371 & 0.235 & 0.224 & 0.376 & 0.284 \\
\hline & PHWE & $0.0001^{*}$ & $0.0119^{\mathrm{NS}}$ & $0.0008 *$ & $0.0981^{\mathrm{NS}}$ & $0.0051^{\mathrm{NS}}$ & $0.1280^{\mathrm{NS}}$ & $0.0843^{\mathrm{NS}}$ & $0.0000^{*}$ & $0.0088^{\mathrm{NS}}$ & $0.0002 *$ & $0.0001 *$ & $0.0051^{\mathrm{NS}}$ & $0.0017^{\mathrm{NS}}$ & $0.0003 *$ & ----- \\
\hline \multirow[t]{8}{*}{ KHAW } & $\mathrm{Na}$ & 3 & 4 & 3 & 4 & 4 & 2 & 4 & 4 & 4 & 3 & 4 & 2 & 4 & 4 & 3.5 \\
\hline & $A r$ & 3 & 4 & 3 & 4 & 4 & 2 & 4 & 4 & 4 & 3 & 4 & 2 & 4 & 4 & 3.5 \\
\hline & Nae & 2.492 & 2.999 & 2.518 & 2.775 & 3.04 & 1.993 & 3.63 & 2.938 & 3.763 & 2.826 & 3.28 & 1.998 & 3.485 & 2.845 & 2.899 \\
\hline & $\mathrm{Ho}$ & 0.429 & 0.457 & 0.457 & 0.371 & 0.514 & 0.371 & 0.429 & 0.457 & 0.429 & 0.429 & 0.486 & 0.400 & 0.343 & 0.457 & 0.431 \\
\hline & $\mathrm{He}$ & 0.599 & 0.666 & 0.603 & 0.64 & 0.671 & 0.498 & 0.724 & 0.66 & 0.734 & 0.646 & 0.695 & 0.500 & 0.713 & 0.649 & 0.643 \\
\hline & 1- $\mathrm{Ho} / \mathrm{He}$ & 0.284 & 0.314 & 0.242 & 0.42 & 0.234 & 0.255 & 0.407 & 0.307 & 0.415 & 0.336 & 0.301 & 0.200 & 0.519 & 0.296 & 0.323 \\
\hline & $F_{I S}$ & 0.298 & 0.327 & 0.228 & 0.431 & 0.247 & 0.268 & 0.420 & 0.298 & 0.413 & 0.349 & 0.314 & 0.213 & 0.530 & 0.308 & 0.332 \\
\hline & PHWE & $0.0525^{\mathrm{NS}}$ & $0.0080^{\mathrm{NS}}$ & $0.1946^{\mathrm{NS}}$ & $0.0004^{*}$ & $0.0073^{\mathrm{NS}}$ & $0.1096^{\mathrm{NS}}$ & $0.0004 *$ & $0.0023 *$ & $0.0000^{*}$ & $0.0005^{*}$ & $0.0026 *$ & $0.2045^{\mathrm{NS}}$ & $0.0000 *$ & $0.0110^{\mathrm{NS}}$ & ----- \\
\hline \multirow[t]{8}{*}{$\overline{\text { BWP }}$} & $\mathrm{Na}$ & 3 & 4 & 4 & 2 & 4 & 3 & 4 & 2 & 4 & 4 & 3 & 4 & 4 & 4 & 3.5 \\
\hline & $A r$ & 3 & 4 & 4 & 2 & 4 & 3 & 4 & 2 & 4 & 4 & 3 & 4 & 4 & 4 & 3.5 \\
\hline & Nae & 2.576 & 3.089 & 3.211 & 1.943 & 2.768 & 2.829 & 3.280 & 1.993 & 3.619 & 2.991 & 2.948 & 3.105 & 2.832 & 3.153 & 2.881 \\
\hline & $\mathrm{Ho}$ & 0.400 & 0.400 & 0.457 & 0.429 & 0.486 & 0.343 & 0.429 & 0.429 & 0.457 & 0.314 & 0.486 & 0.543 & 0.400 & 0.229 & 0.414 \\
\hline & $\mathrm{He}$ & 0.612 & 0.676 & 0.689 & 0.485 & 0.639 & 0.646 & 0.695 & 0.498 & 0.724 & 0.666 & 0.661 & 0.678 & 0.647 & 0.683 & 0.644 \\
\hline & 1-Ho/He & 0.346 & 0.408 & 0.337 & 0.115 & 0.239 & 0.469 & 0.383 & 0.138 & 0.369 & 0.528 & 0.265 & 0.199 & 0.382 & 0.665 & 0.346 \\
\hline & $F_{I S}$ & 0.359 & 0.421 & 0.334 & 0.131 & 0.253 & 0.481 & 0.396 & 0.154 & 0.381 & 0.538 & 0.278 & 0.213 & 0.394 & 0.664 & 0.357 \\
\hline & PHWE & $0.009^{\mathrm{NS}}$ & $0.0000 *$ & $0.1017^{\mathrm{NS}}$ & $0.4372^{\mathrm{NS}}$ & $0.0207^{\mathrm{NS}}$ & $0.0003 *$ & $0.0114^{\mathrm{NS}}$ & $0.3600^{\mathrm{NS}}$ & $0.0011^{*}$ & $0.0000 *$ & $0.1135^{\mathrm{NS}}$ & $0.0000 *$ & $0.0000 *$ & $0.0000^{*}$ & ----- \\
\hline
\end{tabular}


Table 3. Pair-wise population differentiation (below diagonal) and unbiased genetic distance (above diagonal) among the hatchery populations of $C$. carpio.

\begin{tabular}{lcccccc}
\hline Populations & RWP & GUJW & LHR & FSD & KHAW & BWP \\
\hline RWP & ---- & 0.0585 & 0.0799 & 0.0619 & 0.0556 & 0.0636 \\
GUJW & $0.0077^{*}$ & ---- & 0.0622 & $0.0492^{*}$ & 0.0706 & 0.0856 \\
LHR & $0.0174^{*}$ & $0.0079^{*}$ & ---- & 0.0610 & 0.0752 & 0.0899 \\
FSD & $0.0102^{*}$ & $0.0035^{*}$ & $0.0092^{*}$ & --- & 0.0670 & 0.0727 \\
KHAW & $0.0091^{*}$ & $0.0155^{*}$ & $0.0181^{*}$ & $0.0145^{*}$ & ---- & 0.0656 \\
BWP & $0.0126^{*}$ & $0.0216^{*}$ & $0.0241^{*}$ & $0.0169^{*}$ & $0.0150^{*}$ & ---- \\
\hline
\end{tabular}

*Significant at $p<0.05$

Table 4. Analysis of molecular variance (AMOVA) for hatchery populations of C. carpio.

\begin{tabular}{lcccc}
\hline Source of variance & Df & MSS & Variance & \% Variation \\
\hline Among populations & 5 & 10.752 & 0.06585 & 1.37 \\
Among individuals within populations & 204 & 6.142 & 1.41639 & 29.56 \\
Within individuals & 210 & 3.309 & 3.30952 & 69.07 \\
\hline
\end{tabular}

Table 5. Bottleneck analysis for hatchery populations of $C$. carpio.

\begin{tabular}{lccc|cccc}
\hline \multirow{2}{*}{ Populations } & \multicolumn{3}{c}{ Sign test } & \multicolumn{3}{c}{ Wilcoxon test } & \multirow{2}{*}{ Mode shift } \\
\cline { 2 - 6 } & IAM & TPM & SMM & IAM & TPM & SMM & \\
\hline RWP & $0.00018^{*}$ & $0.00043^{*}$ & $0.00050^{*}$ & $0.00003^{*}$ & $0.00003^{*}$ & $0.00003^{*}$ & Shifted \\
GUJW & $0.00024^{*}$ & $0.00053^{*}$ & $0.00056^{*}$ & $0.00003^{*}$ & $0.00003^{*}$ & $0.00003^{*}$ & Shifted \\
LHR & $0.00021^{*}$ & $0.00052^{*}$ & $0.00059^{*}$ & $0.00003^{*}$ & $0.00003^{*}$ & $0.00003^{*}$ & Shifted \\
FSD & $0.00021^{*}$ & $0.00043^{*}$ & $0.00051^{*}$ & $0.00003^{*}$ & $0.00003^{*}$ & $0.00003^{*}$ & Shifted \\
KHAW & $0.00012^{*}$ & $0.00034^{*}$ & $0.00038^{*}$ & $0.00003^{*}$ & $0.00003^{*}$ & $0.00003^{*}$ & Shifted \\
BWP & $0.00013^{*}$ & $0.00035^{*}$ & $0.00042^{*}$ & $0.00003^{*}$ & $0.00003^{*}$ & $0.00003^{*}$ & Shifted \\
\hline
\end{tabular}

*Significant at $p<0.05$

population pairs. The hypothetical grouping of populations was further revealed by AMOVA tests. The results showed that majority of variations $69.07 \%$ lied among the individuals and only $1.37 \%$ differentiation resulted from populations (Table 4). The estimated value of gene flow $(\mathrm{Nm})$ in hatchery populations was observed highest across all the studied loci.

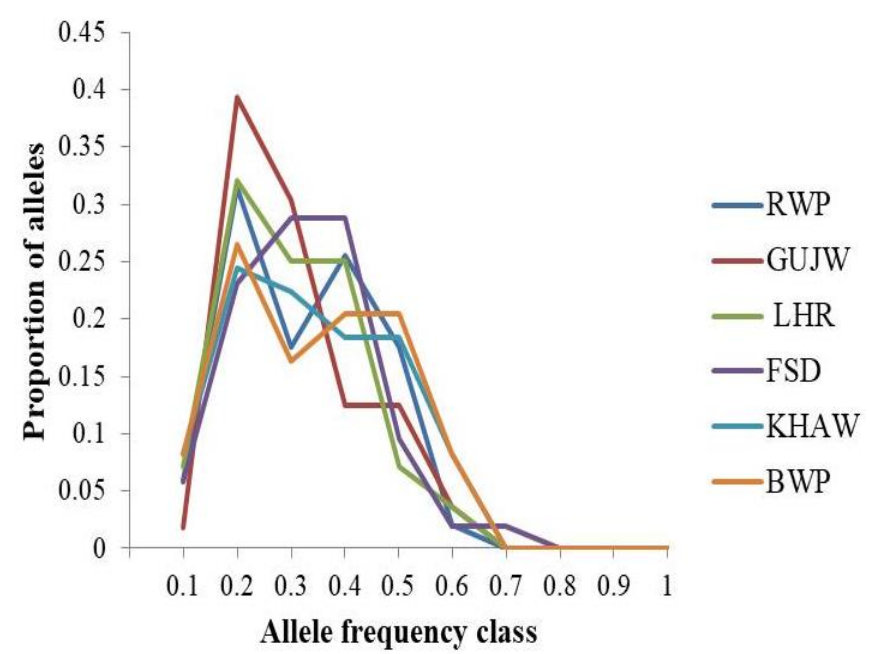

Figure 2. Proportion of alleles and their frequencies in hatchery stocks of $C$. carpio
Bottleneck analysis and mode shift (Fig. 2) in the allele frequency spectrum detected a recent bottleneck in all hatchery populations (Table 5).

The study inferences from STRUCTURE HARVESTER admixture model revealed the consistent results obtained over the 7 autonomous runs. Maximum log likelihood mean value and delta $\mathrm{k}$ was noted for $\mathrm{K}=2$ (Fig. 3). The results were further confirmed by constructing the UPGMA dendrogram that showed two major clusters (Fig. 4). All the populations in first cluster were GUJW, FSD and LHR while the second cluster contained the RWP, KHAW and BWP populations.

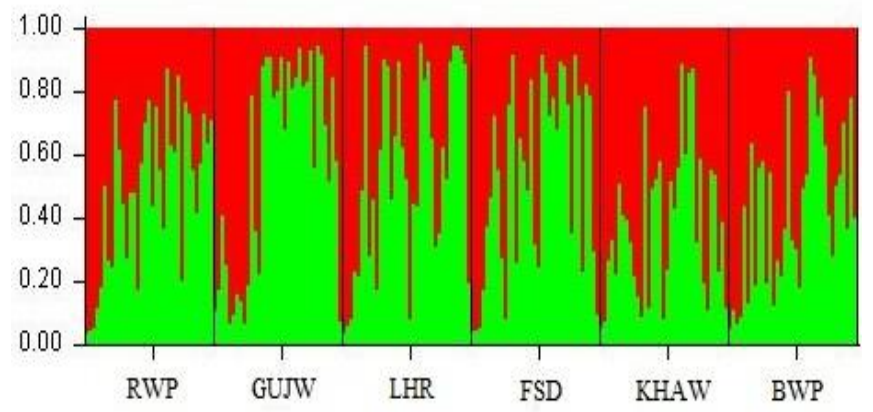

Figure 3. Genetic structuring patterns among $C$. carpio hatchery populations as revealed by STRUCTURE analysis. 
Naz \& Abbas
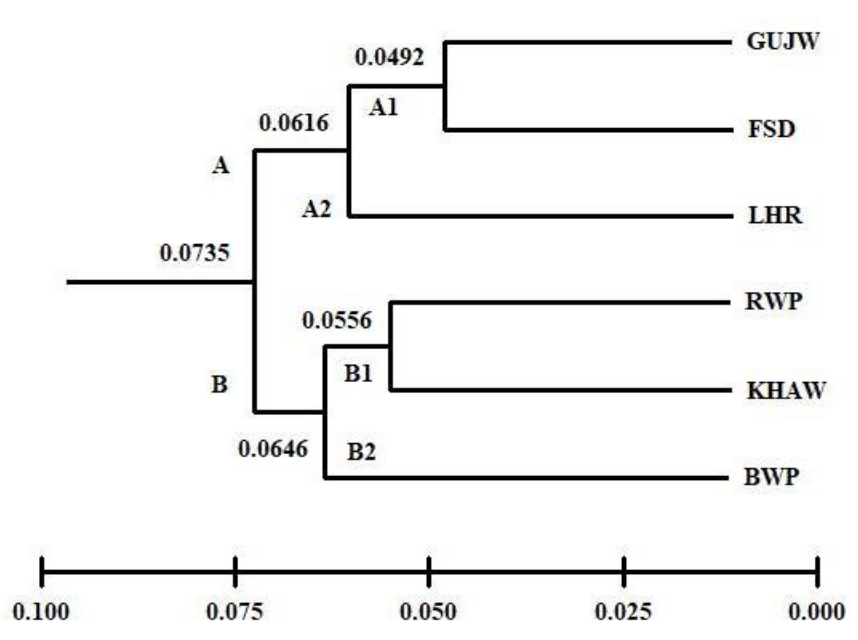

Figure 4. UPGMA dendrogram displaying the relationship and clustering patterns between hatchery stocks of $C$. carpio.

\section{DISCUSSION}

The reduction in fish yield due to genetic degradation has become a major fisheries management issue that can potentially destroy the sustainability of the entire aquaculture business and the effects cannot be mitigated immediately. Awareness over genetic issues, with respect to artificial breeding is low in Pakistan. Several private and public fish hatcheries struggle to protect the potential genetic degradation of cultured and native species via induced spawning techniques. However, due to lack of awareness and technical knowledge, negative selection, possible ecological consequences, extensive inbreeding depression and genetic introgression by harmful hybridization has continued to occur. Therefore, it is imperative to monitor and disclose any change in the genetic structure of the hatchery stocks of $C$. carpio in relation to a base or wild populations.

In this study, low-to-moderate level of genetic diversity was observed in hatchery populations of $C$. carpio. The number of alleles at several microsatellite loci was observed 2 to 5 which are lower than previously reported results about $\mathrm{Na}$ for Catla catla by Ahmed and Abbas (2018). The highest mean number of alleles, allelic richness and effective number of alleles were observed in GUJW population while, the lowest in BWP hatchery population. The change of allelic composition of the hatchery population may be ascribed to the inbreeding and founder effects of artificial and natural selection in the culture environment (An et al., 2011b) and this deficiency is attributed to improper domestication processes happened in the hatchery populations. Equivalent conclusions were reported by Sekino et al. (2002) who detected the reduced number of alleles in hatchery strains of Japanese flounder. Loss of allelic diversity has also been noted for hatchery stocks of Catla catla by Hansen et al. (2006) and for Clarias batrachus by Islam et al. (2007). Tomljanovic et al. (2013) suggested that the reduction of allelic variation in domestic stocks might be the result of founder events or occasional bottleneck effects during the breeding process leading to low effective size $(\mathrm{Ne})$. Heterozygosity acts as an indicator of evolutionary potential and is essential in determining population dynamics as well as population viability (Reed, 2009). The hatchery stocks showed a decline in the observed heterozygosity relative to the expected heterozygosity with the mean values ranged from 0.414 to 0.555 and 0.634 to 0.696 , respectively. This decrease in genetic diversity might correspond to the selection pressure, breeding with limited number of parents and consequently inbreeding depression in hatchery stocks (Li et al., 2016). Parallel findings to ours were reported in a genetic analysis of Labeo rohita by Islam and Alam (2004) and Wenne et al. (2016) but were not consistent with Jewel et al. (2006) who reported the higher level of $\mathrm{Ho}$ and $\mathrm{He}$ in hatchery populations of C. carpio. A loss in heterozygosity values was also supported by the average positive values of $1-\mathrm{Ho} / \mathrm{He}$ and inbreeding coefficient $\left(F_{I S}\right)$ in this study. Comparable results about significant heterozygote deficiencies (positive $F_{I S}$ values) were also reported by Langen et al. (2011) in Pelvicachromis taeniatus from Moliwe and Pelvicachromis pulcher from Nigeria, which might indicate non-random mating but Ceyhun and Ciltas (2013) reported the lower mean observed heterozygosity than the average expected heterozygosity with $F_{I S}$ to be negative in brown trout. After applying multiple test correction, total 32 out of 84 tests in hatchery populations of $C$. carpio was found to deviate from $H W E$ significantly. Several hypotheses including fishing pressure, non-random sampling, inbreeding, wahlund effect, and selection against heterozygote have been mentioned to explain the $H W E$ deviation by Abbas et al. (2010) and Zolgharnein et al. (2011). Consistent results were found by Sultana et al. (2015) who observed the significant deviations from $H W$ equilibrium in domestic stocks of Labeo rohita. Alam and Islam (2005) also revealed that Catla catla population was departed from $H W E$ at a number of microsatellite loci.

The pairwise estimates of $F_{S T}$ revealed the lower genetic differentiation among hatchery stocks of $C$. carpio. The highest level of genetic difference was noted between the population pairs of LHR-BWP while, the lowest between the population pairs of GUJW-FSD. The genetic difference among populations might be triggered by the effect of geographic isolation. The closest relationship with small genetic distance and population differentiation $\left(F_{S T}\right)$ might be due to the geographical similarity among the origins of the two populations and their breeding strategies. Hansen et al. (2006) reported the weaker genetic difference between the Jamuna and the Halda River populations as compared to the captive stocks of Catla catla and suggested the strong genetic drift in hatchery populations. The genetic differentiation between hatchery produces stocks may have been attributed 
to random genetic drift under the stress of artificial selection, which has been well documented in Cyprinus carpio and Thymallus thymallus species (Desvignes et al., 2001; Dawnay et al., 2011). The maximum genetic distance value was noted in the LHR-BWP while, the lowest between the GUJW-FSD, populations pairs. Scribner et al. (1986) and Li et al. (2007) reported that populations living close to each other have higher genetic identities by the effect of gene flow. The findings of the present study of low differentiation in hatchery populations are dissimilar to the findings of Li et al. (2017) who revealed the significant genetic differentiation and high genetic distances in cultured Hemibarbus maculates. AMOVA revealed that most of the variation lies within individuals. These results are in agreement with Nazish et al. (2018) in hatchery populations of Hypophthalmichthys molitrix inferred by microsatellite markers. Gene flow $(\mathrm{Nm})$ values were high, indicating a great gene flow within populations, which might be the main factor of poor genetic difference. There is a negative correlation between $N m$ and FST. The higher the migration rate, the lower is the genetic difference between populations. A bottleneck analysis revealed that the C. carpio hatchery population showed the signs of genetic bottleneck. Similar results about occurrence of recent bottleneck were recorded in populations of the other three species of major carps Labeo calbasu (Saha et al., 2010), Catla catla (Basak et al., 2014), and Cirrhinus cirrhosus (Hasanat et al., 2014), but no evidence of bottleneck was observed in Albanian Cyprinus carpio by Biba et al. (2017). In this study, Construction of UPGMA tree based Nei's standard genetic distance revealed the two distinct clusters, which were further confirmed by the STRUCTURE based microsatellite data analyses. All the populations in first cluster were GUJW, FSD and LHR while the second cluster contained the RWP, KHAW and BWP populations. Despite the greater geographical distance, populations in the same cluster with minimal genetic distance might be that close hatcheries are being managed by the same organization for many years, and using the same spawning material (Memis and Kohlmann, 2006). Other possible reasons could be due to genetic similarity of stocks originating from same origin, conventional mixing of genes and inevitable breeding process for generations in captivity and lack of a genetic management strategy for genetic resources for fish in Pakistan.

The outcomes of the current study defined the genetic status of Cyprinus carpio in hatcheries that can be used as baseline information regarding the genetic variability and population structure before setting any breeding program and for further studies. The $C$. carpio populations are heavily influenced by the inappropriate management practices of hatchery owners and operators as well as weak fisheries policies in the province. The protection of the genetic resources of this species needs a quick attention of the government and the local community so that it could be conserved appropriately and exploited sustainably.

\section{REFERENCES}

Abbas, K., X.Y. Zhou, Y. Li, Z.X. Gao and W.M. Wang. 2010. Microsatellite diversity and population genetic structure of Yellowcheek, Elopichthys bambusa (Cyprinidae) in the Yangtze River. Biochem. Syst. Ecol. 38:806-812.

Ahmed, T. and K. Abbas. 2018. Patterns of genetic variability in natural and hatchery populations of Catla catla based on microsatellite DNA markers. Pak. J. Agric. Sci. 55:929-939.

Alam, M.S. and M.S. Islam. 2005. Population genetics of Catla catla (Hamilton) revealed by microsatellite DNA markers. Aquaculture 246:151-160.

Allendorf, F.W., P.R. England, G. Luikart, P.A. Ritchie and N. Ryman. 2008. Genetic effects of harvest on wild animal populations. Trends Ecol. Evol. 23:327-337.

An, H.S., E.M. Kim, J.H. Lee and J.K. Noh. $2011 \mathrm{~b}$. Population genetic structure of wild and hatchery black rockfish Sebastes inermis in Korea assessed using crossspecies microsatellite markers. Genet. Mol. Res. 10:2492-2504

Bakos, J. and S. Gorda. 2001. Genetic resources of Common Carp at the fish culture research institute, Szarvas, Hungary. Series title: FAO Fisheries Technical Paper No. 417. Rome, FAO. Pp. 106.

Basak, A., A. Ullah, M.N. Islam and M.S. Alam. 2014. Genetic characterization of brood bank collections of the Indian major carp Catla catla (Hamilton) (Cyprinidae:Cypriniformes) by microsatellite DNA markers. J. Anim. Plant Sci. 24:1786-1794.

Biba, A., A. Hoda, V. Bozgo and S. Mali. 2017. Genetic diversity of Cyprinus carpio of natural lakes in Albania estimated by microsatellite loci. . Endocytobiosis Cell Res. 28:1-8.

Boudry, P., B. Collet, F. Cornette, V. Hervouet and F. Bonhomme. 2002. High variance in reproductive success of the Pacific oyster (Crassostrea gigas, Thunberg) revealed by microsatellite-based parentage analysis of multifactorial crosses. Aquaculture 204: 283-296.

Ceyhun, S.B. and A. Ciltas. 2013. Determination of genetic variations of five different indigenous trout species in Turkey (Salmo trutta sp. L.) by microsatellite markers. Turk. J. Fish. Aquat. Sci. 13:785-793.

Choi, C.G. and J.M. Kim. 2012. Detection of Laminariaceae species based on PCR by family-specific ITS primers. Fish. Aquat. Sci. 15:157-162.

Dawnay, N., L. Dawnay, R.N. Hughes, R. Cove and M.I. Taylor. 2011. Substantial genetic structure among stocked and native populations of the European grayling (Thymallus thymallus, Salmonidae) in the United Kingdom. Conserv. Genet. 12:731-744.

Defaveri, J., H. Viitaniemi, E. Leder and J. Merila. 2013. Characterizing genic and nongenic molecular markers: 
comparison of microsatellites and SNPs. Mol. Ecol. Resour. 13:377-92.

Desvignes, J.F., J. Laroche, J.D. Durand and Y. Bouvet. 2001. Genetic variability in reared stocks of Common Carp (Cyprinus carpio L.) based on allozymes and microsatellites. Aquaculture 194:291-301.

Diz, A.P. and P. Presa. 2009. The genetic diversity pattern of Mytilus galloprovincialis in Galician Rias (NW Iberian estuaries). Aquaculture 287:278-285.

Earl, D.A. and B.M. Vonholdt. 2012. STRUCTURE HARVESTER: a website and program for visualizing STRUCTURE output and implementing the Evanno method. Conserv. Genet. Resour. 4:359-361.

Elliott, N.G. and A. Reilly. 2003. Likelihood of bottleneck event in the history of the Australian population of Atlantic Salmon (Salmo salar L.). Aquaculture 215:3144.

Evanno, G., S. Regnaut and J. Goudet. 2005. Detecting the number of clusters of individuals using the software STRUCTURE: a simulation study. Mol. Ecol. 14:26112620.

Excoffier, L., G. Laval and S. Schneider. 2005. Arlequin (version 3.0): An integrated software package for population genetics data analysis. Evol. Bioinform. 1:4750.

Falush, D., M. Stephens and J.K. Pritchard. 2003. Inference of population structure: Extensions to linked loci and correlated allele frequencies. Genetics 164:1567-1587.

Gottschalk, F., C. Ort, R.W. Scholz and B. Nowack. 2011. Engineered nanomaterials in river exposure scenarios for Switzerland at high spatial and temporal resolution. Environ. Pollu. 159:3439-3445.

Goudet, J. 2002. FSTAT Version 2.9.3.2. A program to estimate and test gene diversities and fixation indices. Institute of Ecology, University of Lausanne, Switzerland.

Hansen, M.M., V. Simonsen, K.L.D. Mensberg, M.R.I. Sarder and M.S. Alam, 2006. Loss of genetic variation in hatchery-reared Indian major carp, Catla catla. J. Fish Biol. 69:229-241.

Hasanat, M.A., M.F.A. Mollah and M.S. Alam. 2014. Assessment of genetic diversity in wild and hatchery populations of mrigal Cirrhinus cirrhosis (HamiltonBuchanan) using allozyme markers. Int. J. Fish Aquat. Stud. 1:24-31.

Islam, M.N., M.S. Islam and M.S. Alam. 2007. Genetic structure of different populations of walking Catfish (Clarias batrachus L.) in Bangladesh. Biochem. Genet. 45:647-662.

Islam, M.S. and M.A. Alam. 2004. Randomly amplified polymorphic DNA analysis of four different populations of the Indian major carp Labeo rohita (Hamilton). J. Appl. Ichthyol. 20:407-412.
Jewel, S.A.M., M.M. Rahman and M.N. Islam. 2006. Study of genetic variation in different hatchery populations of Common Carp (Cyprinus carpio) of Mymensingh district in Bangladesh using Microsatellite DNA markers. J. Biosci. 14:113-120.

Kim, W.J., E.H. Shin, H.J. Kong, and B.H. Nam. 2013. Development of polymorphic microsatellite markers suitable for genetic linkage mapping of olive flounder Paralichthys olivaceus. Fish. Aquat. Sci. 16:303-309.

Kohlmann, K., P. Kersten and M. Flajshans. 2005. Microsatellite-based genetic variability and differentiation of domesticated, wild and feral Common Carp (Cyprinus carpio L.) populations. Aquaculture 247:253-266.

Langen, K., J. Schwarzer, H. Kullmann, T.C.M. Bakker and T. Thunken. 2011. Microsatellite support for active inbreeding in a Cichlid Fish. PLoS One 6:1-9.

Lee, H.J. and S.B. Hur. 2012. Comparison between phylogenetic relationships based on $18 \mathrm{~S}$ rDNA sequences and growth by salinity of Chlorella-like species (Chlorophyta). Fish. Aquat. Sci. 15:125-135.

Li, D., D. Kang, Q. Yin, X. Sun and L. Liang. 2007. Microsatellite DNA marker analysis of genetic diversity in wild Common Carp (Cyprinus carpio L.) populations. J. Genet. Genom. 34:984-993.

Li, L., H. Lin, W. Tang, D. Liu, B. Bao and J. Yang. 2017. Population genetic structure in wild and aquaculture populations of Hemibarbus maculates inferred from microsatellites markers. Aquacult. Fish. 2:78-83.

Li, X., Y. Deng, K. Yang, W. Gan, R, Zeng, L. Deng and Z. Song. 2016. Genetic diversity and structure analysis of Percocypris pingi (Cypriniformes: Cyprinidae): Implications for conservation and hatchery release in the Yalong River. PLoS One 11:e0166769.

Loukovitis, D., B. Ioannidi, D. Chatziplis, G. Kotoulas, A. Magoulas and C.S. Tsigenopoulos. 2014. Loss of genetic variation in Greek hatchery populations of the European sea bass (Dicentrarchus labrax L.) as revealed by microsatellite DNA analysis. Mediterranean Marine Sci. 16:197-200.

Memiş, D. and K. Kohlmann. 2006. Genetic characterization of wild Common Carp (Cyprinus carpio L.) from Turkey. Aquaculture 258:257-262.

Miller, M.P. 1997. Tools for Population Genetic Analyses (TFPGA) V 1.3: A Windows Program for the Analysis of Allozyme and Molecular Genetic Data.

Milot, E., C. Perrier, L. Papillon, J.J. Dodson and L. Bernatchez. 2013. Reduced fitness of Atlantic salmon released in the wild after one generation of captive breeding. Evol. App. 6:472-485.

Nazish, N., K. Abbas, S. Abdullah and M.A. Zia. 2018. Microsatellite diversity and population structure of Hypophthalmicthys molitrix in hatchery populations of Punjab. Turk. J. Fish. Aquat. Sci. 18:1113-1122. 
Nei, M. 1972. Genetic distance and molecular phylogeny. N. Ryman and F.M. Utter (Eds.), Population Genetics and Fishery Management. Washington: University of Washington.

Oosterhout, C.V., W.F. Hutchinson, D.P.M. Wills and P. Shipley. 2004. MICRO-CHECKER: Software for identifying and correcting genotyping errors in microsatellite data. Mol. Ecol. Notes, 4:535-538.

Ovenden, R., G.M. Leigh, D.C. Blower, A.T. Jones, A. Moore, C. Bustamante, R.C. Buckworth, M.B. Bennett and C.L. Dudgeon. 2016. Can estimates of genetic effective population size contribute to fisheries stock assessments? J. Fish Biol. 89:2505-2518.

Piry, S., G. Luikart and M.J. Cornuet. 1999. BOTTLENECK: a computer program for detecting recent reductions in the effective population size using allele frequency data. J. Hered. 90:502-503.

Pritchard, J.K., M. Stephens and P. Donnelly. 2000. Inference of population structure using multi locus genotype data. Genetics 155:945-959.

Reed, D.H. 2009. When it comes to inbreeding: slower is better. Mol. Ecol. 18:4521-4522.

Rice, W.R. 1989. Analyzing tables of statistical tests. Evolution 43:223-225.

Saha, D., M. Nahiduzzaman, S. Akter, M.A.R. Hossain and M.S. Alam. 2010. Bottleneck in the endangered kalibaus, Labeo calbasu (Cyprinidae: Cypriniformes) populations in Bangladesh revealed by microsatellite DNA marker analysis. Genes Genom. 32:47-53.

Sambrook, J. and D.W. Russell. 2001. Molecular Cloning: A Laboratory Manual. $3^{\text {rd }}$ Ed. Cold Spring Harbor Laboratory Press, New York, USA.

Scribner, K.T., J.E. Evans, S.J. Morreale, M.H. Smith and J.W. Gibbons. 1986. Genetic divergence among populations of the yellow-bellied slider Turtle (Pseudemys scripta) separated by aquatic and terrestrial habitats. Copeia 1986:691-700.

Sekino, M., M. Harab and N.Taniguchi. 2002. Loss of microsatellite and mitochondrial DNA variation in hatchery strains of Japanese flounder Paralichthys olivaceus. Aquaculture 213:101-122.
Sharpe, D.M.T. and A.P. Hendry. 2009. Synthesis: Life history change in commercially exploited fish stocks: an analysis of trends across studies. Evol. Appl. 2:260-275.

Sultana, F., K. Abbas, Z. Xiaoyun, S. Abdullah, I. Qadeer and R. Hussnain. 2015. Microsatellite markers reveal genetic degradation in hatchery stocks of Labeo rohita. Pak. J. Agric. Sci. 52:775-781.

Tomljanovic, T., T. Treer, V.C. Cubric, T. Safner, N. Sprem, M. Piria, D. Matulic, R. Safner and I. Anicic. 2013. Microsatellite-based genetic variability and differentiation of hatchery and feral Common Carp Cyprinus carpio L. (Cyprinidae, Cypriniformes) populations in Croatia. Arch. Biol. Sci. Belgrade, 65:577584.

Wang, L., Z. Meng, X. Liu, Y. Zhang and H. Lin. 2011. Genetic diversity and differentiation of the OrangeSpotted Grouper (Epinephelus coioides) between and within cultured stocks and wild populations inferred from Microsatellite DNA analysis. Int. J. Mol. Sci. 12:43784394.

Weir, B.S. and C.C. Cockerham. 1984. Estimating F statistics for the analysis of population structure. Evolution 38:1358-1370.

Wenne, R., R. Bernas, A. Pokwierz-Kotus, A. Drywa and A. Was. 2016. Recent genetic changes in enhanced populations of sea trout (Salmo trutta) in the southern Baltic rivers revealed with SNP analysis. Aquat. Living Resour. 29:103-116.

Xu, P., X.F. Zhang, X.M. Wang, J.T. Li, G.M. Liu and Y.Y. Kuang. 2014. Genome sequence and genetic diversity of the Common Carp, Cyprinus carpio. Nat. Genet. 46:1212-1219.

Yeh, F.C., R.C. Yang and T. Boyle. 1999. POPGENE V. 1.31: Microsoft windows-based free software for population genetic analysis. University of Alberta, Edmonton.

Zolghamein, H., M.A.S. Aliabadi, A.M. Forougmand and S. Roshani. 2011. Genetic population structure of Hawksbill turtle (Eretochelys imbricta) using microsatellite analysis. Iran. J. Biotechnol. 1:56-62. 